\title{
Biologia reprodutiva e polinização de Senna sylvestris (Vell.) H.S. Irwin \& Barneby (Leguminosae, Caesalpinioideae)
}

\author{
DANILO A. CARVALHO ${ }^{1}$ e PAULO E. OLIVEIRA ${ }^{2,3}$
}

(recebido: 26 de dezembro de 2002; aceito: 21 de maio de 2003)

\begin{abstract}
Reproductive biology and pollination of Senna sylvestris (Vell.) H.S. Irwin \& Barneby (Leguminosae, Caesalpinoideae)). The reproductive biology of Senna sylvestris was studied in the Panga Ecological Station, Uberlândia and in the Macaúbas district of Patrocínio, Minas Gerais state, Central Brazil. S. sylvestris is a shrub or small tree up to $5 \mathrm{~m}$ which flowers from January to February. Flowers are hermaphrodite, zigomorphous, with an yellow corolla and disposed in paniculate inflorescences. The stigma is wet, non-papillous and crateriform, surrounded by hairs. Anthers are poricidal in a heteranterous androecium, with three staminodia, four small stamens in the upper portion and two larger ones below with another one with a thin anther in between them. S. sylvestris is self-sterile and non-apomictic, with self-sterility involving late-acting selfincompatibility type phenomena. Self- and cross pollen tubes grow to the ovary and penetrate ovules without any detectable diference, but fruits and seeds developed only from cross pollinations using pollen from the two larger anthers. Smaller stamens and even the large one with a thinner anther produced non-viable pollen. These stamens serve as holding places for the visiting bees. Pollen from these anthers may germinate but no fruit resulted from pollination with this kind of pollen. The main visitors and pollinators were large bees Xylocopa brasilianorum, Oxaea flavescens, Bombus morio, and species of Centris and all collect pollen by vibrating the anthers (buzz pollination). Differences in pollinator species richness were observed between sites and study years. Smaller number of pollinators in Macaúbas may be the result of the increased disturbance in that area. However, species richness and number of pollinators did not explain the constantly low fruit set in the studied species.
\end{abstract}

Key words - breeding system, cerrado, Fabaceae, large bees, late-acting self-incompatibility

RESUMO - (Biologia reprodutiva e polinização de Senna sylvestris (Vell.) H.S. Irwin \& Barneby (Leguminosae, Caesalpinoideae)). A biologia reprodutiva de Senna sylvestris foi estudada na Estação Ecológica do Panga (EEP), UberlândiaMG e no distrito de Macaúbas, Patrocínio-MG. S. sylvestris é um arbusto com altura máxima de $5 \mathrm{~m}$ e período de floração entre Janeiro e Abril. As flores são hermafroditas, zigomorfas, com corola de cor amarelo intenso, dispostas em inflorescências do tipo panícula. O estigma é do tipo úmido não papiloso e crateriforme, possuindo pêlos ao seu redor. As anteras são poricidas e o androceu é heterântero, com três estaminódios, quatro estames menores na porção superior da flor, dois estames maiores na porção inferior e entre eles um estame central com antera mais delgada. S. sylvestris é auto-estéril e não agamospérmica, com auto-esterilidade envolvendo fenômenos de ação tardia. Tubos polínicos de autopolinizações e polinizações cruzadas crescem e penetram os óvulos, mas frutos e sementes só se desenvolvem após polinizações cruzadas com anteras grandes. Os estames menores e o central de antera mais delgada, produzem pólen inviável. Estes estames servem apenas como pontos de fixação durante as visitas das abelhas. O pólen das anteras pequenas pode formar tubos polínicos, mas nenhum fruto resultou das polinizações com este tipo de pólen. Os principais visitantes e polinizadores são abelhas grandes Xylocopa brasilianorum, Oxaea flavescens, Bombus morio e espécies do gênero Centris que coletam pólen por vibração das anteras. Foram observadas diferenças na riqueza de espécies de abelhas entre as áreas e entre os anos de estudo. Menor número de polinizadores em Macaúbas pode ser explicado pelo maior grau de perturbação da vegetação. Entretanto diferenças na riqueza e no número de polinizadores não parecem explicar a produção natural de frutos, que foi baixa nas espécies estudadas.

Palavras-chave - abelhas grandes, auto-incompatibilidade de ação tardia, cerrado, Fabaceae, sistema de reprodução

\section{Introdução}

O gênero Senna pertence à subtribo Cassiinae, que inclui, ainda, os gêneros Cassia e Chamaecrista, sendo os três, anteriormente, reunidos no gênero Cassia sensu

1. Faculdades Integradas de Patrocínio, R. Artur Botelho s.n., Chácara das Rosas, 38740-000 Patrocínio, MG; daniloufu@bol.com.br

2. Universidade Federal de Uberlândia, Instituto de Biologia, Caixa Postal 593, 38400-902 Uberlândia, MG, Brasil.

3. Autor para correspondência: poliveira@ufu.br
Bentham (Irwin \& Barneby 1982). Nas Américas, o gênero Senna possui grande diversidade e ampla distribuição, com cerca de 350 espécies. Senna sylvestris (Vell.) H.S. Irwin \& Barneby, fedegoso do mato, é uma espécie com ampla distribuição encontrada nos cerrados e campos abertos do Centro-Oeste, Sudeste e em várzeas e áreas de terra firme da Amazônia Brasileira, podendo ser encontrada em campos na Bolívia, em regiões de vales no Paraguai e Peru, e de maneira geral em pequenas áreas perturbadas nessas 
regiões (Irwin \& Barneby 1982). Nas espécies da subtribo Cassiinae de maneira geral e no gênero Senna em particular, as flores apresentam anteras heteromorfas e de deiscência poricida. As flores não secretam néctar e a polinização geralmente ocorre por abelhas capazes de vibrar os estames para a liberação do pólen, o que caracteriza polinização vibrátil ou "buzz pollination" (Buchmann 1983, Gottsberger \& SilberbauerGottsberger 1988). Estes polinizadores são abelhas grandes (sensu Frankie et al. 1983) que conseguem "abraçar" as peças florais e realizar vibrações (Gottsberger \& Silberbauer-Gottsberger 1988).

Poucos estudos sobre o sistema reprodutivo foram realizados para as espécies de Senna e para as Cassiinae de uma maneira geral. No entanto mecanismos de autoincompatibilidade gametofítica parecem ser comuns na subfamília Caesalpinoideae (Arroyo 1981) e foram inferidos para espécies de Cassiinae com base no tipo de estigma úmido comum entre as espécies do grupo (Owens 1989).

O presente trabalho teve como objetivo estudar a biologia floral, polinização e sistema de reprodução de Senna sylvestis, de forma a compreender parte dos eventos que constituem o ciclo de vida da espécie.

\section{Material e métodos}

O estudo foi realizado em duas etapas: uma entre janeiro e setembro de 1999 e outra entre agosto de 2000 e setembro de 2001, na Estação Ecológica do Panga (EEP), Uberlândia

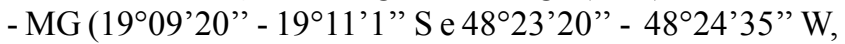
altitude de $800 \mathrm{~m}$ ). No segundo período, uma segunda área, no distrito de Macaúbas, no município de Patrocínio - MG (18 $56^{\prime} 09^{\prime \prime} \mathrm{S}$ e $47^{\circ} 12^{\prime} 58^{\prime \prime} \mathrm{W}$ e $948 \mathrm{~m}$ de altitude), foi utilizada para a coleta de dados comparativos sobre os visitantes florais, sistemas de polinização e biologia reprodutiva. Materiais botânicos, coletados nas áreas de estudo, foram herborizados e depositados no herbário da Universidade Federal de Uberlândia (HUFU) sob os números de registro $18.576,18.577$ e 18.578 .

As observações dos eventos fenológicos foram realizadas somente na Estação Ecológica do Panga (área 1), no período entre agosto de 2000 e setembro de 2001, quando 12 indivíduos foram acompanhados quinzenalmente. Foram observadas as seguintes fenofases: botões florais, flores abertas, frutos (verdes e maduros), queda foliar e brotação. As fenofases foram descritas com notas de intensidade sendo 0 para ausência, 1 para baixa intensidade (até $25 \%$ dos ramos), 2 para intensidade moderada (de $26 \%$ a $60 \%$ dos ramos) e 3 para alta intensidade (mais de $60 \%$ dos ramos).

O período de receptividade estigmática foi determinado pelo método de atividade peroxidásica (Kearns \& Inouye 1993). A viabilidade polínica foi estimada com coloração por carmim acético (Radford et al. 1974) de pólen proveniente dos diferentes tipos de anteras. $\mathrm{O}$ diâmetro dos grãos de pólen dos diferentes tipos de anteras foi medido em lâminas similares às preparadas para viabilidade polínica.

O horário da antese, duração da flor e período de disponibilidade da recompensa para os visitantes (apenas pólen) foram registrados para flores de vários indivíduos em observações diretas no campo. Os tipos de visitantes bem como seu comportamento na flor e a forma de coleta de pólen foram registrados a fim de se caracterizar sua eficiência na polinização. Os visitantes foram observados e coletados, quando possível, ao longo do dia, em 12 indivíduos na EEP e oito indivíduos em Macaúbas. Os períodos de observação e coleta tiveram duração de uma hora, distribuídos ao longo do dia (de 7:00 h às 18:00 h). As observações foram realizadas em intervalos de 30 minutos para cada indivíduo. As observações dos visitantes foram realizadas durante oito dias em ambas áreas de estudo. A freqüência de visitas consistiu em anotar cada vez que a abelha chegava nas inflorescências e visitava as flores.

O sistema reprodutivo da espécie foi estudado com testes de polinizações manuais controladas. Para as polinizações, anteras de flores previamente ensacadas, foram abertas retirando-se os grãos de pólen e colocando-os sobre uma lâmina limpa que foi aplicada contra o estigma das flores receptoras. Foram realizadas autopolinizações e polinizações cruzadas utilizando oito a 10 indivíduos em cada população, distantes pelo menos $50 \mathrm{~m}$ das plantas receptoras. O número de flores utilizadas para os experimentos foi aproximadamente o mesmo para cada indivíduo. Tratamentos de polinizações controladas foram realizados em separado com pólen dos diferentes tipos de anteras das espécies estudadas. Flores previamente emasculadas foram mantidas isoladas para testar a ocorrência de agamospermia. Após os tratamentos, as flores foram mantidas ensacadas até a queda das pétalas. As flores manualmente polinizadas foram monitoradas quinzenalmente para observar a formação de frutos.

Outras flores foram marcadas para estimar a frutificação após a polinização natural. Foi calculado o índice de autoincompatibilidade - ISI (sensu Bullock 1985), para definir o sistema de reprodução predominante.

Uma amostra de flores submetidas à autopolinização e à polinização cruzada foi coletada $24 \mathrm{~h}$ e $48 \mathrm{~h}$ após a antese e fixada em FAA 50\% para observação de crescimento de tubos polínicos em microscopia de fluorescência (método adaptado de Martin 1959). Foram analisados, em separado, pistilos polinizados com pólen proveniente dos diferentes tipos de anteras.

\section{Resultados}

Os indivíduos em ambas as áreas são arbustos com altura máxima de $5 \mathrm{~m}$. Nas duas áreas, indivíduos de 
S. sylvestris encontram-se distribuídos formando aglomerados ou, mais comumente, de forma isolada. $\mathrm{Na}$ Estação Ecológica do Panga (área 1) os indivíduos são encontrados principalmente próximos à borda do cerradão, mas podem ser vistos no cerrado e campo sujo. Em Macaúbas (área 2) os indivíduos são encontrados de maneira esparsa em áreas abertas e alteradas, geralmente próximos à rodovia.

Fenologia - Senna sylvestris possui padrão de floração anual, com maior intensidade nos períodos com maiores índices de precipitação. Em ambas as áreas os indivíduos apresentaram floração e desenvolvimento de frutos semelhantes, não diferindo quanto à época do início e término das fenofases.

No período entre agosto de 2000 e setembro de 2001, a floração mais intensa ocorreu durante os meses de janeiro e fevereiro na EEP (área 1). A floração estendeu-se até o mês de maio, quando foram encontradas poucas flores em alguns indivíduos (figura 1). Os frutos desenvolveram-se ao longo do período de floração e se abriram entre julho e agosto, estando as vagens totalmente livres de sementes em setembro. Os frutos possuem sementes sem arilo ou outras estruturas atrativas, sendo provavelmente autocóricas. Grande parte das sementes foi predada ainda nos frutos, o que comprometeu a abertura dos frutos e dispersão, mesmo das sementes intactas, durante ambos os anos de estudo.

Biologia floral - As inflorescências são panículas terminais com $15 \pm 8,75$ botões por inflorescência $(\mathrm{n}=10)$. Em cada inflorescência abrem-se no máximo cinco flores por dia. As flores têm, em média, $30 \pm$ $10,8 \mathrm{~mm}$ de diâmetro $(\mathrm{n}=5)$, são pentâmeras e zigomorfas e não exalam odores perceptíveis. O cálice é de cor verde-oliva com cinco sépalas iguais; a corola apresenta pétalas membranáceas de cor amarela intensa e com a base ungüiculada, avermelhada (figura 2). As anteras são basifixas, com filetes curtos, aparentemente, muito rígidos, e são poricidas, com dois poros apicais. Anteras e filetes possuem tamanhos diferentes. Existem três grupos de estames de tamanhos diferentes, num total de sete estames aparentemente férteis, além de três estaminódios na porção superior da flor. Um grupo de quatro estames centrais apresenta anteras e filetes curtos, tendo 7,9 $\pm 1,5 \mathrm{~mm}(\mathrm{n}=6)$ de comprimento. $\mathrm{Na}$ porção inferior da flor (figura 2) localizam-se dois estames com anteras bem maiores, 13,7 $\pm 2,1 \mathrm{~mm}$ de comprimento $(n=5)$. Entre estes dois estames maiores, há um terceiro estame com antera delgada, bem diferenciada, mas de comprimento similar. A posição do pistilo e da região estigmática muda de flor para flor, ficando à direita ou à esquerda da antera grande delgada e caracterizando enantiostilia. Flores dos dois morfos ocorrem indiscriminadamente em uma mesma inflorescência e em freqüência similar na população.

A abertura completa das flores ocorre a partir das 7:00 h, mas nesse momento os poros apicais das anteras ainda estão fechados. Ao longo da manhã, com o aumento da temperatura, os poros apicais das anteras se abrem e o pólen pulverulento torna-se disponível para os visitantes.

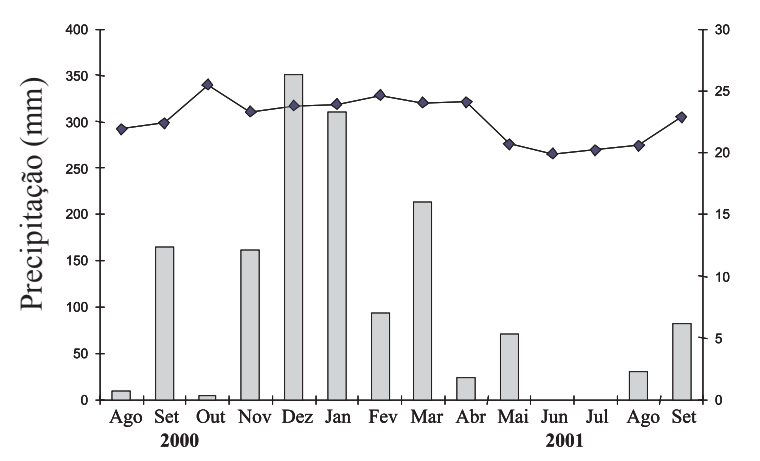

A

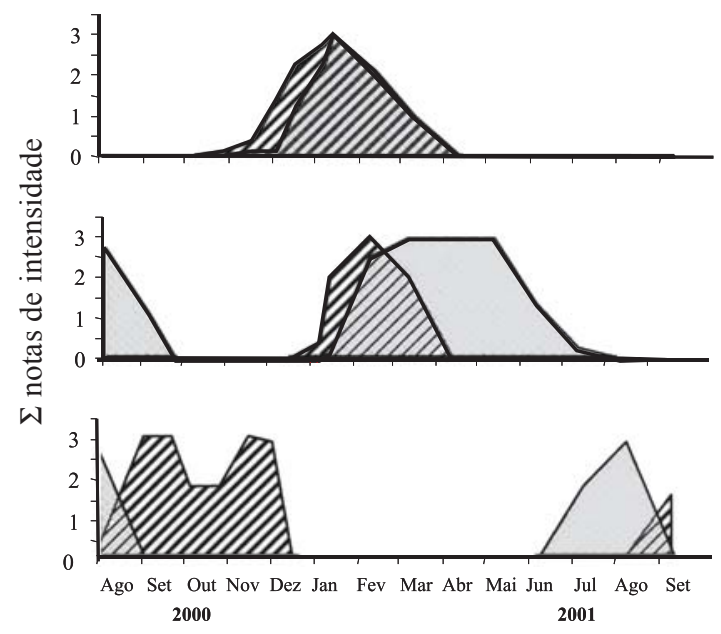

B

Figura 1. Fenologia reprodutiva de Senna sylvestris na Estação Ecológica do Panga (EEP). A. Precipitação e temperatura para o período de agosto de 2000 a setembro de 2001 (dados da estação climatológica do Parque do sabiá, $35 \mathrm{~km}$ da EEP). B. Fenograma da intensidade de cada fenofase durante o mesmo período (média das notas de intensidade). $\square=$ botões, frutos verdes, brotação; $\mathbb{Z}=$ flores, frutos maduros, queda foliar.

Figure 1. Reproductive phenology of Senna sylvestris at the Panga Ecological Station (EEP). A. Rain fall and temperature from August 2000 to September 2001 (data from the climatological station of the "Parque do Sabiá", $35 \mathrm{~km}$ North the EEP). B. Phenological diagram showing the intensity of each phenophase during the same period (average of phenological intensity scores). $\square=$ buds, immature fruits, sprouting; $\square=$ flowers, mature fruits, leaves falling. 

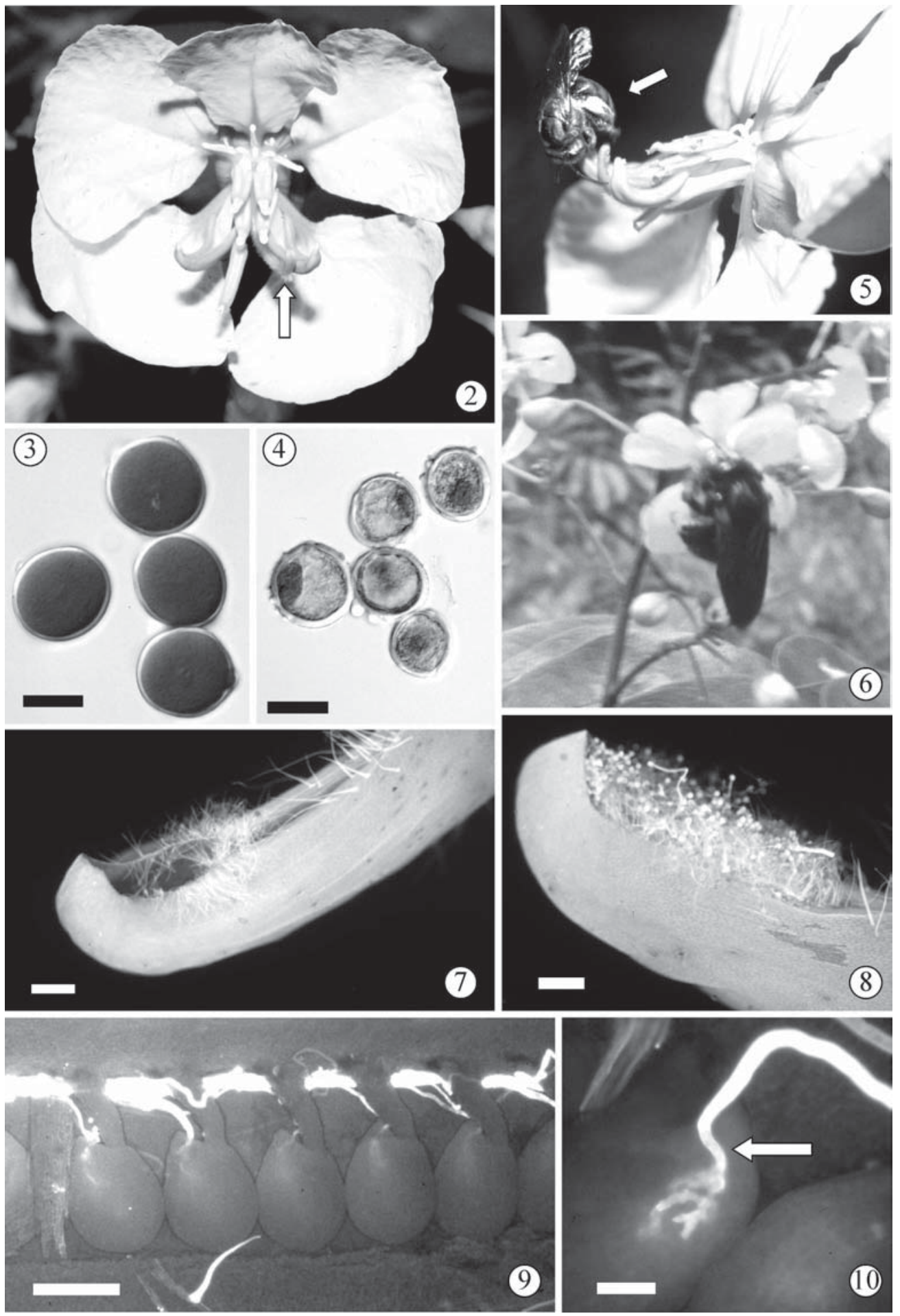

Figuras 2-10. Aspectos da morfologia e biologia reprodutiva de Senna sylvestris. 2. Vista frontal da flor aberta mostrando as anteras heteromorfas e enantiostilia, com o estigma fora do plano de simetria (seta). 3. Grãos de pólen das anteras maiores corados com carmim acético. 4. Grãos de pólen das anteras centrais menores mostrando citoplasma aparentemente menos denso em coloração com carmim. 5. Pseudaugochlora graminae vibrando as anteras grandes de uma flor de Senna sylvestris; note-se o pólen coletado nas escopas (seta). 6. Xylocopa cf. brasilianorum realizando coleta vibrátil de pólen. 7. Estigma não polinizado observado sob microscopia de fluorescência. 8. Estigma 24 h após polinização cruzada, mostrando germinação profusa de grãos de pólen. 9. Corte longitudinal de pistilo $48 \mathrm{~h}$ após polinização cruzada mostrando tubos polínicos crescendo ao longo da placenta e penetrando os óvulos. 10. Detalhe da penetração de um tubo polínico num óvulo $48 \mathrm{~h}$ após polinização cruzada (Escala $=25 \mu \mathrm{m}$ nas figuras 3, 4 e 10; $250 \mu \mathrm{m}$ nas figuras 7 e 8 ; e $100 \mu \mathrm{m}$ na figura 9). 
Com exceção dos estaminódios, os testes de viabilidade do pólen dos três grupos de estames indicaram que todos são potencialmente férteis, com coloração de todas as amostras com carmim acético (97,5\% e 99,6\%), indicando citoplasma ativo. Entretanto, os grãos de pólen tiveram coloração de intensidades diferentes. As duas anteras maiores e laterais apresentaram pólen com coloração mais acentuada (figura 3) que os da antera mediana delgada e os do grupo de anteras menores centrais, que possuem um citoplasma menos denso e com grande vacúolo (figura 4). Os grãos de pólen das duas anteras maiores laterais são maiores $(0,667 \pm 0,00722 \mu \mathrm{m})$ que o das anteras menores centrais $(0,492 \pm 0,00453 \mu \mathrm{m})$ e da mais delgada $(0,481 \pm 0,00366 \mu \mathrm{m})$, sendo tal diferença estatisticamente significativa $(\mathrm{P}<0,001)$. Mas não foram observadas diferenças significativas entre $\mathrm{o}$ tamanho dos grãos de pólen das quatro anteras menores e da maior mais delgada $(\mathrm{P}>0,05)$.

$\mathrm{O}$ estigma alongado e crateriforme mantém-se receptivo desde o botão em pré-antese até 24 horas após a flor aberta. As flores ficam abertas por um dia e no final da tarde a corola fecha-se sobre os estames e o pistilo. As pétalas, então, tornam-se esbranquiçadas. Durante o segundo dia após a abertura o cálice, a corola e as anteras caem, deixando apenas o pistilo, que sem polinização efetiva cai no terceiro dia após a abertura da flor.

Visitantes florais - A espécies é visitada e polinizada por abelhas. Houve diferenças marcadas entre os visitantes observados nos dois anos de estudos na Estação Ecológica do Panga (EEP) e diferenças menores entre esta área e a área 2 (Macaúbas). Em 1999 foram observadas somente visitas da abelha Pseudaugochlora graminae na área da EEP (figura 5). Em contraste, no ano de 2001 foi observado um total de oito espécies de abelhas vibradoras na EEP (área 1), pertencentes às famílias Apidae, Halictidae, Anthophoridae e Oxaeidae (tabela 1). Além das espécies de abelhas, foi coletada uma espécie de Diptera da família Asilidae que apenas pousava nas flores. De maneira geral o número de espécies que visitam $S$. sylvestris na EEP foi maior que em Macaúbas (tabela 1), sendo que Oxaea flavescens e as espécies do gênero Centris não foram observadas visitando $S$. sylvestris na área 2. Por outro lado, Melipona quinquefasciata foi observada somente em Macaúbas. A freqüência de visitas mostra também que este número ao longo do dia foi maior na EEP do que em Macaúbas (figura 11).

As observações durante o ano de 2001, nas áreas 1 e 2, totalizaram oito dias. Xylocopa cf. brasilianorum foi visitante muito freqüente em ambas áreas de estudo, e dado seu tamanho e comportamento de visitação, vibrando efetivamente a flor e contatando facilmente o estigma, pode ser considerada o polinizador mais efetivos de Senna sylvestris. Oxaea flavescens, Exomalopsis sp., Centris sp., Bombus morio e Pseudaugochlora graminae foram outros visitantes importantes, mas a efetividade dessas abelhas como polinizadores aparentemente variou com o tamanho e comportamento na flor.

A maior atividade das abelhas coincide com a ocasião em que as anteras já se encontram com os poros abertos e com o pólen disponível. O pico de atividade dos visitantes florais se dá pela manhã entre 9:00 h e 13:00 h, com diferenças pequenas entre as duas áreas de estudo (figura 11). As abelhas Xylocopa cf. brasilianorum, Oxaea flavescens, Centris sp. e Bombus morio possuem padrão de visita semelhante, chegando e saindo das plantas numa mesma direção, o que sugere a manutenção de rotas de forrageamento ("trap lining") entre os indivíduos de $S$. sylvestris. Essas abelhas têm comportamento semelhante durante a coleta de pólen. As abelhas aproximam-se frontalmente das flores e antes de pousarem, geralmente giram em volta da flor como em reconhecimento. Ao pousarem, abraçam os estames e o pistilo com todas as pernas e fazem a vibração do corpo, que provoca a liberação do pólen (figura 6). Não foi observado se durante a visita elas se agarram aos estaminódios com as mandíbulas, como

Figures 2-10. Aspects of the morphology and reproductive biology of Senna sylvestris. 2. Front view of an open flower showing heteromorphic anthers and enantiostily, with the stigma outwith the plane of symmetry (arrow). 3. Pollen grains from the larger dorsal anthers stained with acetic carmine. 4. Pollen grains from the smaller central anthers with cytoplasm apparently less dense under acetic carmine staining. 5. Pseudaugochlora graminae vibrating the larger anthers of a Senna sylvestris; note pollen on the scopa (arrow). 6. Xylocopa cf. brasilianorum buzzing a flower for pollen. 7. Unpollinated stigma under fluorescence microscopy. 8. Stigma $24 \mathrm{~h}$ after cross pollination with profuse pollen germination. 9 . Longitudinal section of a pistil $48 \mathrm{~h}$ after cross pollination showing pollen tubes growing along the placenta and penetrating the ovules. 10. Detail of a pollen tube penetrating an ovule $48 \mathrm{~h}$ after cross pollination (Scale bar $=25 \mu \mathrm{m}$ in figures 3,4 and 10; $250 \mu \mathrm{m}$ in figures 7 and 8; and $100 \mu \mathrm{m}$ in figure 9). 
Tabela 1. Visitantes de S. sylvestris na EEP (área 1) e Macaúbas (área 2) no período entre janeiro e abril de 2001. A tabela destaca a área onde foram avistados e a freqüência de visitas, que foi definida a partir da somatória das observações nas duas áreas: + são visitas ocasionais em até $10 \%$ das sessões de observação, ++ são visitas freqüentes em $40 \%$ das sessões e +++ são muito freqüentes acima de $60 \%$ das sessões.

Table 1. Visitors to S. sylvestris flowers in the EEP (area 1) and Macaúbas (area 2) between January and April 2001. The table indicates the area where the species was observed and observation frequency, which was defined after the sum of observations in both areas: + for occasional visits in less than $10 \%$ of the observation sessions, ++ for frequent visits at least in $40 \%$ of the observation sessions, and +++ for very frequent visits in $60 \%$ or more of the observation sessions.

\begin{tabular}{|c|c|c|c|c|}
\hline \multirow[t]{2}{*}{ Família } & \multirow[t]{2}{*}{ Espécie } & \multicolumn{2}{|c|}{ Área } & \multirow{2}{*}{$\begin{array}{c}\text { Freqüência de } \\
\text { visitas }\end{array}$} \\
\hline & & 1 & 2 & \\
\hline \multirow[t]{3}{*}{ APIDAE } & Trigona spinipes (Fabricius, 1793) & $\mathrm{X}$ & $\mathrm{X}$ & +++ \\
\hline & Bombus morio (Swedeus) & $\mathrm{X}$ & $\mathrm{X}$ & + \\
\hline & Melipona quinquefasciata (Lepeletier, 1836) & & $\mathrm{X}$ & +++ \\
\hline HALICTIDAE & Pseudaugochlora graminae (Fabricius) & $\mathrm{X}$ & $\mathrm{X}$ & ++ \\
\hline \multirow[t]{5}{*}{ ANTHOPHORIDAE } & Xylocopa cf. brasilianorum (Linnaeus) & $\mathrm{X}$ & $\mathrm{X}$ & +++ \\
\hline & Centris (Melanocentris) sp. & $\mathrm{X}$ & & + \\
\hline & Centris (Centris) sp. & $\mathrm{X}$ & & + \\
\hline & Centris (Paremisia) sp. & $\mathrm{X}$ & & + \\
\hline & Exomalopsis (Phanomalopsis) sp. & $\mathrm{X}$ & $\mathrm{X}$ & + \\
\hline OXAEIDAE & Oxaea flavescens (Klug, 1807) & $\mathrm{X}$ & & $+1+$ \\
\hline ASILIDAE (DIPTERA) & Não identificada & & $\mathrm{X}$ & + \\
\hline
\end{tabular}

descrito em outros estudos de polinização vibrátil. A deposição de pólen nas abelhas ocorre na região ventral. As abelhas podem visitar em seqüência cinco a 10 flores totalmente abertas numa mesma planta. As visitas não duram mais de 5 segundos, sendo que após a visita a abelha abandona a flor. Algumas abelhas, como as espécies de Centris, limpam o pólen depositado na região ventral do seu corpo, levando o pólen para as escopas.

Pseudaugochlora graminae, a única abelha observada em 1999, e Exomalopsis sp., apresentam comportamento de visita diferente das demais abelhas devido ao seu pequeno tamanho. Elas pousam em uma das pétalas da flor e caminham para um dos estames maiores, que estão no mesmo nível do estigma. Sobre apenas uma antera, a abelha vibra seu corpo provocando a liberação do pólen (figura 5). Abelhas trigonas foram observadas predando intensamente os estames cedo pela manhã. Sua presença diminui por volta das 9:00h, quando se inicia a visita de abelhas vibradoras. As flores com estames perfurados e parcialmente predados foram observadas sendo visitadas normalmente por abelhas vibradoras.

Sistema reprodutivo - Senna sylvestris é uma espécie auto-incompatível e não apomítica (tabela 2), com índice de auto-incompatibilidade (ISI) de 0,06 (para o ano de 1999). Além disso, somente frutos provenientes de polinizações cruzadas com grãos de pólen das anteras

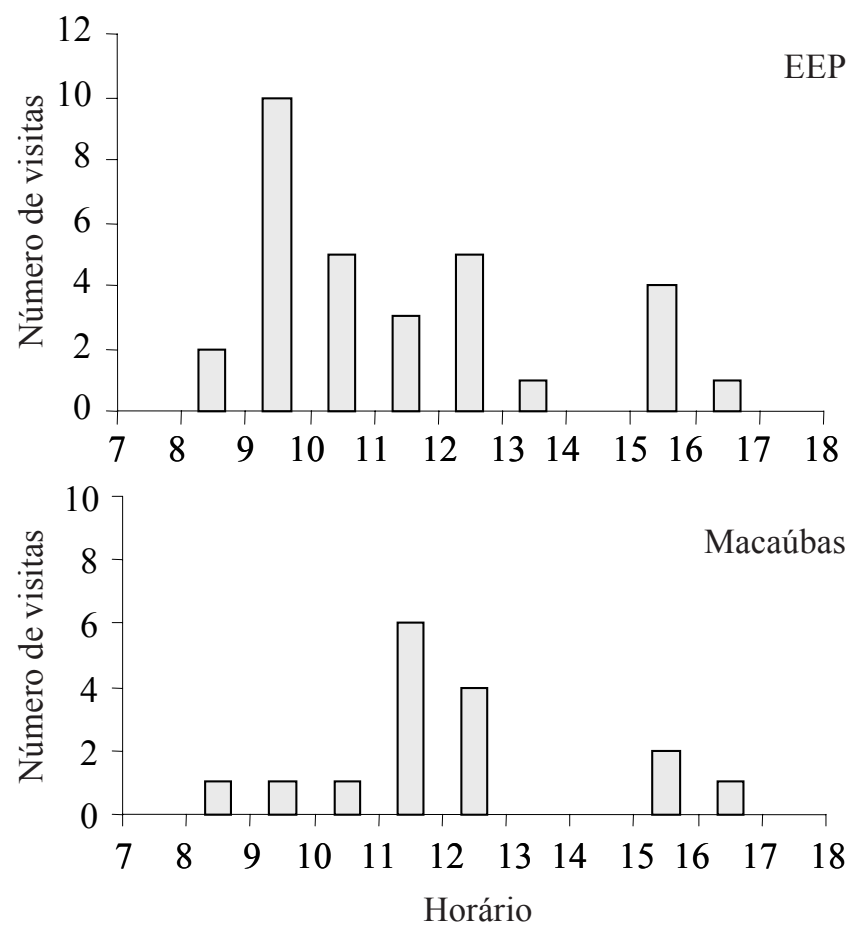

Figura 11. Freqüência dos visitantes a flores de indivíduos de $S$. sylvestris na EEP (área 1) e em Macaúbas (área 2), em observações ao longo do dia, durante um período de oito dias de estudo no ano de 2001.

Figure 11. Frequency of visitors to flowers of S. sylvestris at EEP (area 1) and Macaúbas (area 2) observed throughout the day during eight consecutive days in 2001. 
grandes se desenvolveram perfeitamente até a maturação. Os cruzamentos realizados com grãos de pólen de anteras pequenas centrais não resultaram na formação de frutos (tabela 2). Alguns cruzamentos realizados com pólen das anteras grandes mais delgadas (não quantificados) também não resultaram na formação de frutos.

O estigma é amplo (figura 7) e o pólen tanto de polinização cruzada quanto de autopolinização mostra germinação profusa $24 \mathrm{~h}$ após o tratamento (figura 8). Entretanto, as observações de microscopia de fluorescência mostraram um pequeno número de tubos polínicos crescendo ao longo dos pistilos, indicando que esse tempo deva ser insuficiente para o crescimento. Após um intervalo maior de tempo, 48 horas após a antese, podem ser vistos em ambos os tratamentos, tubos polínicos crescendo profusamente ao longo de todo estilete, chegando ao ovário (figura 9) e penetrando nos óvulos (figura 10). Não foram observadas diferenças aparentes na quantidade nem na velocidade de crescimento dos tubos polínicos originados de autopolinização e polinização cruzada. $\mathrm{O}$ método utilizado não permite definir se ocorreu efetivamente fertilização nos óvulos penetrados.

Em muitos dos pistilos polinizados com grãos de pólen de anteras menores centrais e da antera grande mais delgada, não foi observada germinação ou crescimento de tubos polínicos. Quando alguma germinação foi observada, os tubos polínicos apresentaram crescimento aparentemente menos vigoroso e foram menos numerosos, quando comparados com tubos polínicos em pistilos polinizados com pólen das duas anteras grandes laterais. Mas mesmo estes tubos menos numerosos e vigorosos puderam alcançar os óvulos e penetrá-los após $48 \mathrm{~h}$. No entanto, como mencionado, somente polinizações cruzadas realizadas com pólen das duas anteras grandes laterais acarretaram a formação de frutos. $\mathrm{O}$ aborto dos pistilos autopolinizados ocorreu gradualmente de dois dias até uma semana após os cruzamentos.

\section{Discussão}

Senna sylvestris apresenta aspectos da morfologia floral semelhantes aos de outras espécies da subtribo Cassiinae (Gottsberger \& Silberbauer-Gottsberger 1988). No entanto, entre as espécies dessa subtribo, uma extraordinária diferenciação morfológica das peças florais pode ser observada, incluindo mudanças de forma do perianto, número e disposição dos estames férteis e em características do gineceu (Gottsberger \& Silberbauer-Gottsberger 1988). Muitas dessas

Tabela 2. Resultados das polinizações controladas em indivíduos de Senna sylvestris, estudados na EEP (área 1) no ano de 1999 (oito indivíduos), e das polinizações realizadas no ano de 2001, incluindo polinizações com pólen das anteras menores centrais, na EEP (10 indivíduos) e Macaúbas (oito indivíduos).

Table 2. Results of hand pollination experiments in S. sylvestris, studied in the EEP (area 1) in 1999 (eight individuals), and hand pollinations carried out in 2001, including pollinations with pollen from the smaller central anthers, in the EEP (10 individuals) and Macaúbas (eight individuals).

\begin{tabular}{|c|c|c|c|}
\hline Tratamentos & Flores & Frutos & $\%$ \\
\hline \multicolumn{4}{|l|}{ EEP(Área 1) 1999} \\
\hline Polinização cruzada (anteras maiores laterais) & 83 & 20 & 24,1 \\
\hline Autopolinização (anteras maiores laterais) & 71 & 1 & 1,4 \\
\hline Autopolinização espontânea & 36 & 0 & 0,0 \\
\hline Agamospermia & 34 & 0 & 0,0 \\
\hline Controle (polinização natural) & 212 & 3 & 1,4 \\
\hline \multicolumn{4}{|l|}{ EEP (Área 1) 2001} \\
\hline Polinização cruzada (anteras maiores laterais) & 17 & 9 & 52,9 \\
\hline Autopolinização (anteras menores centrais) & 9 & 0 & 0,0 \\
\hline Polinização cruzada (anteras menores centrais) & 49 & 0 & 0,0 \\
\hline \multicolumn{4}{|l|}{ Macaúbas (Área 2) 2001} \\
\hline Polinização cruzada (anteras menores centrais) & 56 & 0 & 0,0 \\
\hline Autopolinização (anteras menores centrais) & 30 & 0 & 0,0 \\
\hline Controle (polinização natural) & 100 & 10 & 10,0 \\
\hline
\end{tabular}


mudanças, que podem ser observadas desde o início da ontogenia das flores, estão associadas a uma crescente zigomorfia e especialização floral (Tucker 1996).

Os estames heteromorfos observados nas espécies de Cassiinae podem favorecer dois tipos de utilização do pólen: para polinização e para alimentação (Vogel 1978). Lopes \& Machado (1996) observaram que as flores de Swartzia pickelii (Leguminosae-Faboideae) apresentam um tufo de 110 estames pequenos na porção superior da flor e quatro estames maiores na porção inferior, todos com anteras de deiscência longitudinal. De acordo com esses autores, os estames na porção superior da flor, têm função de atração e fornecem pólen para alimentação, contudo tal pólen também é viável, podendo ser responsável pela fecundação e desenvolvimento dos frutos. Os dados aqui apresentados para Senna sylvestris confirmam que os grãos de pólen provenientes das anteras menores centrais não são eficientes para a fertilização, nem tampouco parecem servir como pólen de alimentação. Estes estames apresentam grãos de pólen menores, suas anteras possuem ápices mais agudos e poros menores que parecem dificultar a sua liberação. É possível que este grupo de estames centrais funcione, juntamente com os estaminódios, apenas para auxiliar a fixação de abelhas grandes durante as visitas. Os três estaminódios e as quatro anteras menores centrais comuns em espécies de Senna parecem ser modificações dos 10 estames geralmente encontrados na subfamília Caesalpinioideae e parecem ter surgido durante a irradiação da subtribo Cassiinae devido à pressão por economia de pólen decorrente do tipo especializado de polinização vibrátil. Vogel (1978) considera que flores que oferecem apenas pólen como recompensa (floresde-pólen) devem ter sofrido uma pressão para limitar o acesso de abelhas, cada vez mais eficientes, ao pólen que é necessário para o processo de polinização. Nesse sentido, flores-de-pólen menos especializadas apresentariam grande quantidade de pólen comumente num grande número de anteras de deiscência longitudinal, facilmente acessíveis aos visitantes florais, enquanto em flores mais eficientes e derivadas, o pólen estaria disponível em menor quantidade e protegidos em algumas poucas anteras poricidas, que exigem comportamento especializado dos polinizadores.

Senna sylvestris parece ser morfologicamente bem adaptada à polinização por abelhas grandes e solitárias que apresentam capacidade de vibração das anteras "buzz pollination" (Buchmann 1983). O pólen pulverulento e o estigma relativamente mais amplo do que os descritos para outras espécies de Cassiinae
(Owens 1989), deveria resultar numa maior eficiência de polinização e formação de frutos em Senna sylvestris. Mas a produção de frutos foi, de maneira geral, limitado, especialmente no primeiro ano do estudo onde a principal abelha observada parece ter sido ineficiente para a polinização cruzada efetiva.

As flores de Senna sylvestris possuem cores bastante evidentes, o que possibilita a atração visual a longa distância por abelhas coletoras exclusivas de pólen que são polinizadoras de outras espécies de Cassiinae (Silberbauer-Gottsberger \& Gottsberger 1988). Abelhas do gênero Xylocopa e Oxaea, os principais visitantes e polinizadores de $S$. sylvestris, são visitantes de outras espécies de Senna e de Cassiinae investigadas até o momento (Silberbauer-Gottsberger \& Gottsberger 1988). Estas são abelhas grandes que "abraçam" as peças florais e usualmente contatam o estigma da flor com a parte ventral do tórax ou abdômen. A estratégia de forrageamento das abelhas parece seguir o padrão do tipo linha de captura ("trap-lining" sensu Janzen 1971). Abelhas que realizam "trap-lining" são eficientes na transferência de pólen entre indivíduos distantes de populações pequenas, como ocorre com Senna sylvestris, podendo favorecer assim a polinização cruzada.

A enantiostilia, registrada para espécies dos gêneros Senna e Cassia (Irwin \& Barneby 1982) e para outras espécies com anteras poricidas em diversas famílias entre as angiospermas (Buchmann 1983), é uma outra característica que pode aumentar as possibilidades de polinização cruzada. Em S. sylvestris as flores de ambos os morfos ocorrem numa mesma inflorescência e as abelhas visitantes parecem receber o pólen indistintamente na região ventral, podendo tocar indiscriminadamente os estigmas de flores de outros morfos. Mas mesmo nessas condições, dados sobre freqüência de polinização de flores com enantiostilia sugerem que a polinização cruzada é favorecida (Jesson \& Barrett 2002).

Senna sylvestris é auto-incompatível e apresenta auto-esterilidade de ação tardia, como muitas das espécies lenhosas de cerrado estudadas até o momento (Oliveira \& Gibbs 2000). O fenômeno de autoincompatibilidade de ação tardia (sensu Seavey \& Bawa 1986, Sage et al. 1994) encontrado na espécie aqui estudada ainda não havia sido descrito para o gênero Senna, apesar deste sistema reprodutivo ser comumente encontrado em outras espécies de leguminosas tropicais (Gibbs \& Bianchi 1999, Gibbs et. al. 1999). A ausência de mecanismos claros de retenção dos tubos polínicos no estigma e estilete e atraso no aborto dos pistilos 
autopolinizados torna difícil diferenciar estes fenômenos de auto-esterilidade (LSI) de processos de depressão endogâmica (Gibbs et al. 1999). Muitos estudos têm destacado a presença de LSI e discutido os possíveis mecanismos envolvidos em plantas do bioma cerrado, como em Vellozia squamata Pohl. (Oliveira et al. 1991), Dalbergia miscolobium Benth. (Gibbs \& Sassaki 1998), Hymenaea stigonocarpa Mart. ex Hayne (Gibbs et al. 1999) e Casearia grandiflora Camb. (Machado \& Oliveira 2000). No entanto, a rejeição de pistilos autopolinizados por mecanismos de depressão endogâmica somente são sugeridos para espécies onde pistilos autopolinizados e frutos jovens são abortados irregularmente após períodos de semanas ou meses (Oliveira et al. 1991, Gibbs \& Bianchi 1999). Aborto de pistilos autopolinizados após um período definido de tempo, como em S. sylvestris e também em Hymenaea stigonocarpa (Gibbs et al. 1999), sugere que algum mecanismo específico de incompatibilidade de ação tardia deve estar envolvido.

Agradecimentos - Ao Peter E. Gibbs pelas sugestões e correções nas primeiras versões do manuscrito. À Isabel Alves dos Santos e Kleber Del Claro pela identificação dos visitantes. O trabalho foi realizado no âmbito do Programa Centro-Oeste de pesquisa e Pós-graduação, CNPq (ref. 52.0848/99-3) e Projeto Integrado 520872/96-7.

\section{Referências bibliográficas}

ARROYO, M.T.K. 1981. Breeding systems and pollination biology in Leguminosae. In Advances in Legume Systematics (R.M. Polhill \& P.H. Raven, eds.) (Part 2). Royal Botanic Gardens, Kew, p.723-769.

BUCHMANN, S.L. 1983. Buzz pollination in Angiosperms. In Handbook of experimental pollination biology (C.E. Jones \& R.J. Little, eds.). Van Nostrand Scientific and Academic Editions, New York, p.73-113.

BULLOCK, S.H. 1985. Breeding systems in the flora of tropical deciduous forest in México. Biotropica 17:287-301.

FRANKIE, G.W., HABER, W.A., OPLER, P.A., \& BAWA, K.S. 1983. Characteristics and organization of the large bee pollination system in the Costa Rican dry forest. In Handbook of experimental pollination biology (C.E. Jones \& R.J. Little, eds.). Van Nostrand Scientific and Academic Editions, New York, p.411-447.

GIBBS, P.E. \& SASSAKI, R. 1998. Reproductive Biology of Dalbergia miscololobium (LeguminosaePapilionoideae) in SE Brazil: the effect of pistilate sorting on fruit-set. Annals of Botany 81:735-740.
GIBBS, P.E. \& BIANCHI, M.B. 1999. Does late-acting selfincompatibily (LSI) show family clustering? Two more species of Bignoniaceae with LSI : Dolichandra cynanchoides and Tabebuia nodosa. Annals of Botany 84:449-457.

GIBBS, P.E., OLIVEIRA, P.E. \& BIANCHI, M.B. 1999. Postzygotic control selfing in Hymenaea stigonocarpa (Leguminosae-Caesalpinoideae), a bat-pollinated tree of the Brazilian cerrados. International Journal of Plant Science 160:72-78.

GOTTSBERGER, G. \& SILBERBAUER-GOTTSBERGER, I. 1988. Evolution of flower structures and pollination in Neotropical Cassiinae (Caesalpiniaceae) species. Phyton 28:293-320.

IRWIN, H.S. \& BARNEBY, R.C. 1982. The American Cassiinae. Memoirs of the New York Botanical Garden 35:1-918.

JANZEN, D.H. 1971. Euglossine bees as long-distance pollinators of tropical plants. Science 171:203-205.

JESSON, L.K. \& BARRETT, S.C.H. 2002. Solving the puzzle of mirror-image flowers. Nature 417:707.

KEARNS, C.A. \& INOUYE, D.W. 1993. Techniques for pollination biologists. University of Colorado Press, Niwot.

LOPES, A.V.F.E. \& MACHADO, I.C.S. 1996. Biologia floral de Swartzia pickelli (Leguminosae-Papilionoideae) e sua polinização por Eulaema spp. (Apidae-Euglossinae). Revista Brasileira de Botânica 19:17-24.

MACHADO, A.O. \& OLIVEIRA, P.E. 2000. Biologia floral de Casearia grandiflora Camb. (Flacourtiaceae). Revista Brasileira de Botânica 23:283-290.

MARTIN, F.N. 1959. Staining and observing pollen tubes in the style by means of fluorescence. Stain Technology 34:125.

OLIVEIRA, P.E., GIBBS, P.E. \& BIANCHI, M. 1991. Pollination and breeding system of Vellozia squamata (Liliales: Velloziaceae): a species of the Brazilian cerrados. Botanica Acta 104:345-404

OLIVEIRA, P.E. \& GIBBS, P.E. 2000. Reproductive biology of woody plants in a cerrado community of Central Brazil. Flora 95:311-329.

OWENS, S.J. 1989. Stigma, style, pollen, and the pollenstigma interaction in Caesalpinoideae. In Advances in legume biology (C.H. Stirton \& J.L. Zarucchi, eds.). Monographs in Systematic Botany from the Missouri Botanic Garden 29:113-126.

RADFORD, A.E., DICKSON, W.C., MASSEY, J.R. \& BELL, C.R. 1974. Vascular plant systematics. Harper and Row, New York.

SAGE, T.L., BERTIN, R.I. \& WILLIAMS, E.G. 1994. Ovarian and other late-acting self-incompatibility systems. In Genetic control of self-incompatibility and reproductive development in flowering plants (E.G. Williams, A.E. Clarke \& R.B. Knox, eds.). Kluwer Academic Publishers, Dordrecht, p.116-140.

SEAVEY, S.R. \& BAWA, K.S. 1986. Late-acting selfincompatibily in angiosperms. Botanical Review 52:195-219 
TUCKER, S. 1996. Trends in evolution of floral ontogeny in Cassia sensu stricto, Senna, and Chamaecrista (Leguminosae: Caesalpinoideae: Cassieae: Cassiinae); a study in convergence. American Journal of Botany 83:687-711.
VOGEL, S. 1978. Evolutionary shifts from reward to deception in pollen flowers. In Pollination of flowers by insects (A.J. Richards, ed.). Academic Press, London, p.89-96. 